\title{
Emergencia indígena en Michoacán. Ejercicio de derechos de facto y de jure
}

\section{Indigenous emergence in Michoacán. Practice of de facto and de jure rights}

doi: http://dx.doi.org/10.32870/

espiral.v25i73.7041

\section{Resumen}

En este artículo se analiza la diversidad del movimiento indígena en la Meseta P'urhépecha, en Michoacán, México, a partir de un seguimiento documental y etnográfico realizado durante las últimas tres décadas. Progresivamente, se exponen los procesos principalmente políticos que explican esta irrupción indígena;se discuten las vías de facto y de jure que han construido las comunidades indígenas para exigir el respeto a su derecho a la autonomía, así como sus tensiones y contradicciones; se examina la naturaleza política del denominado Consejo Supremo Indígena de Michoacán (CSIM), que agrupa a más de treinta comunidades; se revisan críticamente los alcances jurídicos de las distintas iniciativas de ley en materia indígena; $y$ se presentan algunas reflexiones sobre los desafíos que tienen las comunidades para consolidar sus procesos autonómicos.

Palabras clave: derechos indígenas, autonomía, presupuesto directo, consulta, cuarto ámbito de Gobierno.

\author{
María del Carmen Ventura Patiño
}

\begin{abstract}
This article analyzes the diversity that characterizes the indigenous movement in the Meseta P'urhépecha, in Michoacán, Mexico, based on documental research and ethnographic fieldwork conducted over the past three decades. Progressively, it traces the -primarily political- processes that explain this indigenous revival, and discusses the de facto and de jure pathways that led to the construction of these indigenous communities and the demand that their right to autonomy to be respected. Also, the existing tensions and contradictions and the political status of the Supreme Indigenous Council of Michoacán (CSIM), which brings together over thirty communities, are discussed. Finally, this article presents a critical review of the juridical achievements of various legislative initiatives regarding indigenous affairs, before concluding with reflections about the challenges these communities face to consolidate their processes of autonomy.
\end{abstract}

Keywords: Indigenous rights, autonomy, direct budget, consultations, fourth level of government.

-Profesora-Investigadora del Centro de Estudios Rurales de El Colegio de Michoacán (COLMICH), México. ORCID: http://orcid.org/0000-000I-6II0-6835_ventura@colmich.edu.mx Fecha de recepción: 05 de marzo de 2018. Fecha de aceptación: 21 de junio de 2018. 


\section{Introducción}

La emergencia indigena es un término que fue referido por José Bengoa (2000) para explicar la irrupción de los indígenas en nuestro continente, quienes habían permanecido silenciosos por varias décadas y que a fines del siglo $\mathrm{XX}$ aparecieron con sus antiguas identidades cuestionando la entrada a la modernidad. Con su aparición, no sólo reivindicaron una serie de derechos en tanto colectividades culturalmente diferentes, sino apelaron a la propia reconfiguración de los llamados Estados nación y obligaron a algunos Gobiernos nacionales a incluir la cuestión indigena en sus agendas políticas y a reescribir sus constituciones para incluirlos como parte de los ahora denominados Estados plurinacionales, como en los casos de Ecuador y Bolivia. México formó parte de esta activa participación indígena: en 1994, cuando el entonces presidente Carlos Salinas de Gortari anunció la entrada de México al primer mundo, los zapatistas se levantaron en armas. Su voz, demandas y movimiento resonaron no sólo en nuestra cartografía nacional, sino también en América Latina, como lo señala José Bengoa (2000).

En este trabajo, se busca exponer cómo esta irrupción étnica, en estrecha relación con procesos regionales y locales, fue dando lugar a un diverso movimiento indígena en el estado de Michoacán, México, uno de los estados que ha sido partícipe en la construcción de organizaciones comunitarias que apelan a una serie de demandas indígenas y optan por distintas vías para su reconocimiento. Se considera que la emergencia indígena en Michoacán y sus nuevas y diversas expresiones han estado imbricadas de manera contenciosa con procesos de ejercicio de derechos de facto y con la apelación del reconocimiento y respeto a los mismos en las instancias judiciales, lo que algunos autores denominan la justiciabilidad de los derechos (Sierra, 2014; González 
y Mesri, 2015), es decir, que los actores se ven obligados a recurrir a las instancias judiciales para exigir que se respeten sus derechos reconocidos por el marco jurídico nacional e internacional.

Este movimiento indígena en Michoacán tiene sus antecedentes en la década de los noventa del siglo Xx, y ha estado permeado por dos procesos nacionales: el ya comentado zapatismo, y el inicio de una oleada de reformas jurídicas en materia indígena, principalmente a partir del 2001.

Una de estas reformas fue al artículo $2^{\circ}$ de nuestra constitución, de la cual derivó una serie de reformas en la mayoría de las entidades federativas. Otra reforma de relevancia es la que se efectuó al artículo $1^{\circ}$ constitucional, en materia de derechos humanos, en 2011. Aunado a ello, también se ha vivido lo que puede denominarse el giro político de las instancias judiciales como la propia Suprema Corte de Justicia de la Nación (SCJN) y el Tribunal Electoral del Poder Judicial de la Federación (TEPJF), que por medio de sus sentencias y resoluciones han reconfigurado su larga relación de subordinación frente al Poder Ejecutivo. De ser un poder pasivo, como bien afirma Pilar Domingo, "la Suprema Corte se ha constituido en un poder efectivo en términos de control constitucional y de legalidad dentro del sistema político" (Domingo, 2007, p. 36).

En contraste con este panorama federal, las iniciativas de los legisladores en Michoacán han buscado acotar los alcances de los derechos de los indígenas y promover una mayor intromisión del Estado en los asuntos de su vida interna. De este modo, se sostiene que el derecho se ha constituido como un campo en disputa entre distintos actores gubernamentales, fuerzas políticas, organizaciones étnicas y comunidades indígenas que buscan definir sus contenidos y su interpretación. En el centro del debate, subyace la tensión entre el reconocimiento de derechos colectivos y la primacía de los derechos individuales, esto es, entre una ciudadanía 
liberal, que sólo reconoce a los individuos como sujetos de derecho, y una ciudadanía comunal activa, que exige por medio de la vía de facto, pero cada vez más de jure, el respeto de los derechos de las comunidades indígenas como sujetos colectivos con derecho a tener derechos.

En el plano político, a fines del siglo XX algunas de las demandas indígenas en Michoacán se centraban en: 1) la contienda por la presidencia municipal, esto es, que un indígena ocupara el principal cargo de representación en el municipio; 2) la creación de nuevos municipios, principalmente en aquellas comunidades subordinadas a cabeceras municipales mestizas (Ramírez, 2007, p. 3), abogando por la conformación de municipios indígenas; y 3) la integración de regiones autónomas pluriétnicas (RAP), propuestas por organizaciones indígenas (Ventura, 2003a). Estas demandas empezaron a formularse, principalmente, ante el desencanto provocado por el sistema de partidos y la democracia electoral en las comunidades indígenas, a fines de 1990.

Desde sus primeras administraciones, los Gobiernos perredistas empezaron a reproducir las viejas prácticas priistas, de corrupción y clientelismo, lo que trajo consigo el cuestionamiento de miembros de comunidades indígenas que habían defendido los triunfos con tomas de carreteras y alcaldías. Dichos indígenas denunciaron la continuidad de la discriminación económica y, sobre todo, la exclusión política de la que fueron objeto en el caso de los principales cargos de representación en el ayuntamiento. Las luchas de facciones que antes tenían al Partido Revolucionario Institucional (PRI) como principal espacio para su expresión ahora también se dirimían al interior del Partido de la Revolución Democrática (PRD). Por lo tanto, la disputa por las candidaturas trajo consigo la división y posterior fractura y debilitamiento del PRD y, por consecuencia, el retorno del PRI a los ayuntamientos michoacanos. Esto sucedió, por 
ejemplo, en la comunidad de Tarecuato, perteneciente al municipio de Tangamandapio (Ventura, 2003b).

Un proceso similar se vivió en el municipio de Paracho. Para las elecciones municipales de 2004, se presentaron al interior del PRD seis precandidatos, todos ellos mestizos habitantes de la cabecera. Sin embargo, su incapacidad para llegar a acuerdos políticos tuvo un costo en los resultados electorales: el contrato político entre los dirigentes perredistas de la cabecera y los militantes de las comunidades, consistente en que el candidato a la presidencia surgiría de la cabecera y el resto de los cargos de representación recaería en miembros de las comunidades, se agotó en esta contienda electoral, por lo que su derrota fue una crónica anunciada. Después de cinco trienios perredistas, el PRI regresó al poder municipal, como sucedió en muchos otros municipios perredistas de la Meseta P'urhépecha.

Las aspiraciones indígenas a ser Gobierno, en sus distintas expresiones, estaban permeadas por el movimiento zapatista de Chiapas, pero fueron cobrando mayor fuerza, entre otros factores, conforme creció el desencanto por el sistema partidista y la democracia electoral. Esta experiencia generó nuevos procesos: algunas comunidades del municipio de Paracho, que acordaron no participar en las elecciones y no permitir la instalación de las casillas en el proceso electoral de 2004, empezaron a ejercer derechos de facto.

Una comunidad en particular se declaró autónoma, la de Nurío. En esta comunidad, se celebró el tercer Congreso Nacional Indígena, en 2001, como parte de las actividades de la Marcha Color de la Tierra, realizada por el Ejército Zapatista de Liberación Nacional (EZLN), un recorrido por la república que tenía el objetivo de llegar a la máxima tribuna del país, el Congreso de la Unión, para exigir la inclusión del reconocimiento de los derechos indígenas en la carta magna. Además, Nurío sería una de las comunidades que visitaría el Delegado Zero, subcomandante del EZLN, en 
un nuevo recorrido por el país, a propósito de su propuesta política La Otra Campaña, en 2006, que promulgaba el llamado a no votar.

A continuación, se presentan algunos de los procesos comunales. A través de sus acciones organizativas y reivindicativas, las comunidades indígenas michoacanas han exigido de facto y de jure que se respeten sus derechos como sujetos colectivos, lo que ha redefinido la relación entre las instituciones del Estado y las propias comunidades, e incidido en el plano jurídico, de modo que el derecho se ha convertido, como ya se dijo, en un campo en disputa entre diversos actores, quienes buscan definir sus contenidos y su interpretación. El propósito último del presente texto es mostrar la diversidad del movimiento indígena en el estado de Michoacán.

\section{Ejercicio de derechos de facto en Quinceo y Nurío. ¿Cuarto ámbito de Gobierno?}

A partir del controvertido proceso electoral de 2004 en el municipio de Paracho y del retorno del PRI a dicho ayuntamiento, las comunidades de Quinceo y Nurío acordaron, cada una por su lado, que sin importar qué partido estuviera en el poder municipal exigirían a las autoridades la parte proporcional del presupuesto municipal. Además, crearon sus denominados consejos comunales, integrados por autoridades y exautoridades, civiles y agrarias, y por comuneros nombrados por la asamblea comunal. En dichos consejos discuten los principales asuntos comunales y toman acuerdos. Sus miembros acuden juntos a las dependencias para la gestión o negociación de lo acordado.

En el caso de la comunidad de Quinceo, se dieron un paso adelante y dos atrás. A principios de 2005, sus autoridades elaboraron un plan de desarrollo comunal para tres años que fue avalado por la asamblea. A través de este, lograron que en 
2005 y 2006 el ayuntamiento les diera MXN 1750 000.00, y para 2007 obtuvieron MXN 2000 000.00, con los cuales realizaron obras públicas importantes para la comunidad. Además, consiguieron que las autoridades comunales recibieran una compensación mensual y se cubrieran los sueldos de cuatro policías de la comunidad.

Sin embargo, ha habido un retroceso en los acuerdos logrados. Para el 2016, según informa uno de los comuneros, apenas se ejercía el presupuesto de 2015, que ascendió a MXN 2900 000.00, y para diciembre de 2016 aún no les había sido entregado lo que les correspondía para dicho año fiscal. Con los recursos de 2015, se realizaron algunas obras: MXN 600000.00 se destinaron a infraestructura para escuelas básicas, MXN 1000000.00 a la escuela de bachillerato, y el resto a la pavimentación de calles.

Estas obras las realiza el ayuntamiento, por lo que las autoridades comunales ya no reciben el presupuesto en sus manos, sino que sólo indican al ayuntamiento las obras que quieren que se ejecuten. Además, se les destina del gasto corriente un monto para la compensación de las autoridades comunales y para el pago de diez policías.

El Consejo Comunal se reúne cada dos meses, pero ahora está integrado por miembros de partidos: seis del PRD, cuatro o cinco del PRI, tres o cuatro del Partido Acción Nacional (PAN) y uno del Partido del Trabajo (PT) (entrevista personal, 2016f), por lo que los intereses partidarios están presentes en las decisiones de esta instancia. Esto implica una vuelta a la anterior relación del ayuntamiento con las comunidades, es decir, a que la definición del presupuesto, su control y manejo queden sujetos a las decisiones del presidente municipal, o, en todo caso, del cabildo, donde los miembros de las comunidades no tienen injerencia. Además, la instancia ampliada para la discusión y el acuerdo de los asuntos comunales ha quedado cooptada por los partidos políticos. 
En el caso de Nurío, el proceso ha sido distinto. El logro referente a la redistribución, el manejo, el control y la administración de los recursos municipales ejercidos por parte de las autoridades comunales fue resultado del proceso organizativo de estas y de su capacidad de negociación con representantes del Gobierno estatal. La comunidad acudió, a mediados de 2005, con el secretario de Gobierno, para exigir que se les entregara directamente la parte proporcional del presupuesto municipal. Tras varias negociaciones, y pese al señalamiento del propio funcionario estatal de que dicha entrega directa no era posible porque no estaba contemplada en el marco jurídico, se acordó, con la presencia del presidente municipal, que se entregarían los recursos a Nurío. Dicho acuerdo se había mantenido hasta el 2016, no sin tensiones y momentos ríspidos vividos con los distintos presidentes municipales de filiación perredista y priista de los últimos trece años.

Los recursos que ha logrado obtener la comunidad de Nurío los ha destinado a obras comunales acordadas y vigiladas por la asamblea comunal, esto a través de comités de obras específicos. En sus manos está todo el proceso de administración, que incluye la realización de cotizaciones, la compra de material, la realización de las obras con miembros de la comunidad y la entrega de facturas y comprobaciones al ayuntamiento.

La comunidad de Nurío logró en el primer trienio de su declaración de autonomía que le fuera entregado un monto considerable de recursos, el cual ha ido en aumento: en 2005 recibió MXN 1300 000.00; en 2006 MXN 2750 000.00, y en 2007 MXN 3800 000.00. Sus logros alcanzados también incluyeron un apoyo económico para los gastos de traslado de los jefes de tenencia y el representante de bienes comunales, por un monto de MXN 1500.00 quincenales. El presupuesto municipal destinado a Nurío proviene de los 
fondos III de Obras Públicas, IV de Seguridad Pública y el denominado de gasto corriente.

Además, la comunidad logró en 2005 que se pagara el sueldo y se les dotara de uniformes a cuatro policías nombrados por la comunidad, que habían estado dando ese servicio de manera gratuita; para el 2007, el número de policías pagados ascendió a diez. Así también, los integrantes de la comunidad consiguieron que se les diera una patrulla para el servicio de vigilancia comunal.

De esta manera, Nurío emprendió el camino en el ejercicio de derechos de facto, sin esperar a su reconocimiento en el plano legal ni invocando el derecho indígena nacional e internacional en las instancias judiciales. La demanda actual de muchas comunidades indígenas del presupuesto municipal directo encuentra su antecedente en la comunidad de Nurío, no sólo por su experiencia organizativa y de gestión, sino también por su capacidad de administración y vigilancia de los recursos, lo que le ha permitido, no sin problemas, hacer un manejo eficiente de los mismos para la realización de un mayor número de obras comunales, las cuales, de haber estado bajo el control de los ayuntamientos, no hubieran sido posibles.

Nurío también es referente porque fue pionera en la organización de seguridad comunitaria, como un elemento que, junto con sus instancias de decisión y su organización social, contribuyó a que el crimen organizado no hubiera alcanzado en dicha comunidad los niveles de violencia que se han experimentado en otras. No se trata de ver a dicha comunidad como armónica y libre de conflictos, sino de dar cuenta de una experiencia comunitaria que ha dado pasos significativos para constituirse como su propia interlocutora frente al Estado, al margen de los partidos políticos, y de su capacidad de crear instancias para dirimir las diferencias, discutir los distintos proyectos comunitarios y mostrar una 
idea de unidad y con la fuerza necesaria para ejercer de facto derechos no reconocidos.

Hasta la fecha, la comunidad de Nurío sigue recibiendo la parte proporcional de los recursos municipales. En 2016, se le destinaron alrededor de ocho millones de pesos, correspondientes a los tres fondos: obras, gasto corriente y seguridad (entrevista personal, 2016g). La imbricación de sus instituciones de Gobierno en el ámbito agrario, civil, judicial y religioso, junto con el consejo comunal y la asamblea, así como el control de su administración, expresan el ejercicio de un cuarto ámbito de Gobierno.

\section{Cherán y Pichátaro. Justiciabilidad de los derechos}

Como ya han señalado varios estudios (Velázquez, 2013; Santillán, 2014), la comunidad de Cherán emprendió una serie de acciones en defensa de su seguridad ante las constantes violaciones por parte de miembros del crimen organizado, que ellos denominan los malosos, y ante la incursión de estos en la explotación ilegal de sus bosques.

La comunidad vivió un momento de crisis política tras el cuestionado proceso electoral municipal de noviembre de 2007. La confrontación política entre distintas facciones comunales, que dirimían sus diferencias por medio de los partidos políticos, trajo consigo el asesinato de uno de sus líderes, la toma de la presidencia municipal por parte de los comuneros inconformes y la solicitud de la desaparición de poderes, que les fue negada por parte del Congreso local. Ante esta negativa, el a mbiente de ingobernabilidad obligó al edil a trasladar las oficinas municipales a otro lugar. Este era el escenario comunal cuando se empezaron a recrudecer los hechos de violencia: extorsiones, secuestros, desapariciones y asesinatos, cuyos autores estaban ligados, a decir de los comuneros, con el presidente municipal impugnado. 
La reacción comunal de defensa, que consistió en la detención de los narcotalamontes, ${ }^{1}$ la construcción de barricadas y la ejecución de todo un dispositivo organizativo para repeler cualquier agresión por parte del crimen organizado, fue conocida como el levantamiento de Cherán, en abril de 2011. Las células que dieron vida a esta forma de organización fueron las llamadas fogatas, casi doscientas, ubicadas en la convergencia de casi todas las esquinas de los cuatro barrios de la comunidad. Las fogatas se constituyeron en espacios claves, no sólo como estrategia organizativa de defensa, sino como lugares de discusión sobre los asuntos de la vida interna comunitaria.

La tibia respuesta gubernamental federal y estatal ante la petición comunal de que se brindara protección, así como la última experiencia en la contienda electoral, fueron elementos que estuvieron presentes en las discusiones comunales frente al nuevo proceso electoral, que se realizaría en noviembre de 2011. Algunos de los líderes que encabezaron o participaron de manera activa en este proceso de defensa también habían formado parte de las mencionadas luchas de facciones; años atrás, habían sido miembros destacados al interior de los partidos, y algunos de ellos habían ocupado cargos en el ayuntamiento, tenían acercamiento con el EZLN, se habían apropiado de los discursos y reivindicaciones zapatistas, y eran miembros del Congreso Nacional Indígena (CNI). Todos estos procesos explican por qué la propuesta de no participar en la contienda electoral generó cierto consenso entre los miembros de la comunidad.

Si bien el acuerdo comunal consistió en no participar en los procesos de elección para renovar los poderes Legislativo y Ejecutivo locales y, por tanto, no permitir que dentro de su territorio se realizaran campañas y se instalaran las casillas

I. Se refiere al vínculo entre taladores clandestinos de madera y los grupos del crimen organizado. 
electorales, esto no significó que los miembros de la comunidad no participaran en la renovación del poder municipal. En asamblea celebrada en junio de 2011, los comuneros decidieron que el nombramiento, que no elección, de sus autoridades municipales sería a través de lo que denominan usos y costumbres. Un joven abogado cheranense, junto con otros abogados de la Universidad Michoacana de San Nicolás de Hidalgo (UMSNH), diseñaron la estrategia legal para dar sustento a la propuesta y gestionar ante el Instituto Electoral de Michoacán (IEM) el ejercicio del derecho de nombrar a sus autoridades comunales, reconocido en el marco jurídico internacional.

Sin duda, una coyuntura jurídica importante fue la reforma al artículo $1^{\circ}$ constitucional, ya mencionada, en junio de 2011, a través de la cual se confirió rango constitucional a los derechos humanos reconocidos en el marco jurídico nacional y en los tratados internacionales, lo cual implica que la interpretación de las normas de derechos humanos debe realizarse favoreciendo en todo tiempo a las personas la protección más amplia.

Uno de los rasgos más importantes de la reforma es que, al reconocer explícitamente la protección constitucional de los tratados internacionales de derechos humanos, se convierte en una motivación, legitimación, e incluso obligación para los operadores jurídicos de incorporar parámetros internacionales en su actuar. En muchas ocasiones se observaba cierta reticencia por parte de jueces para la inclusión de tratados internacionales como fundamento de sus sentencias (Orozco, 20I I, p. 97).

De este modo, una vez que el Consejo General del IEM se declaró sin atribuciones para atender la solicitud de Cherán de celebrar las elecciones bajo el principio de usos y costumbres, la comunidad promovió un juicio para la protección de sus derechos político-electorales ante el TEPJF, cuya resolución fue favorable, sustentada en el marco jurídico 
internacional y nacional, en particular el recién modificado artículo $1^{\circ}$ constitucional, señalando que

"[...] la comunidad indígena de Cherán tiene derecho a solicitar la elección de sus propias autoridades, siguiendo para ello sus normas, procedimientos y prácticas tradicionales, con pleno respeto a los derechos humanos". Como bien señaló uno de los magistrados, Pedro Penagos, durante su pronunciamiento en favor de la propuesta del magistrado presidente: "a los actores les asiste la razón" (Tribunal Electoral del Poder Judicial de la Federación, 20I I, citado en Ventura, 20I2, p. 167).

Este primer triunfo jurídico representó para Cherán un respaldo importante en la construcción de esta vía de jure. La comunidad no sólo nombró a sus autoridades municipales de acuerdo con sus propios procedimientos, sino que además organizó una estructura del poder municipal distinta a la señalada por la constitución en su artículo 115, que establece que el ayuntamiento se integra por un presidente municipal, un síndico y regidores. La comunidad de Cherán nombró un Concejo Mayor de Gobierno Comunal, conformado por tres miembros de cada uno de los cuatro barrios del municipio, además de una serie de concejos operativos que forman la estructura de Gobierno. El reconocimiento de esta nueva forma de Gobierno no estuvo libre de tensiones, pero finalmente la comunidad obtuvo la declaración de validez por parte del IEM, el respaldo del Congreso local y la entrega de recursos del Gobierno estatal.

Otro recurso legal que invocaron los miembros de la comunidad como mecanismo de jure fue la controversia constitucional presentada ante la SCJN por haber sido violado su derecho a la consulta respecto a la reforma indígena que fue aprobada por el Congreso en diciembre de 2011. Los diputados se vieron obligados a aprobar una iniciativa en materia indígena, que había sido relegada de la agenda legislativa por cerca de un año, para cumplir con 
el mandato establecido en la misma resolución del TEPJF que favoreció a Cherán. En mayo de 2014, la SCJN emitió su sentencia, por medio de la cual reconoció a Cherán el carácter de municipio indígena, resultado de un amplio debate entre los ministros de la sala respecto a si Cherán era comunidad agraria, comunidad indígena o municipio, y qué tipo de municipio.

Los ministros señalaron que el ayuntamiento de Cherán fue elegido por usos y costumbres, derecho que le fue reconocido por el TEPJF, por lo que se consideró cosa juzgada. Para una de las ministras, el ayuntamiento de Cherán tiene todas las obligaciones de cualquier otro, sólo que posee autoridades sui generis (Suprema Corte de Justicia de la Nación, 2014, p. 31). Ese carácter de municipio sui generis, apuntó otro de los ministros, "le da la oportunidad para defender no sólo las condiciones de cualquier municipio, sino en especial la del pueblo indígena que lo conformó [...] se le debe reconocer un carácter especial, que pudiéramos llamar un municipio indígena" (Suprema Corte de Justicia de la Nación, 2014, p. 35).

Por su parte, el Poder Legislativo no pudo acreditar que consultó al municipio de Cherán. En suma, la SCJN resolvió: 1) que era procedente y fundada la controversia constitucional presentada; y 2) que se declaraba la invalidez, con efectos únicamente entre las partes, de la reforma hecha a la Constitución de Michoacán de Ocampo (Suprema Corte de Justicia de la Nación, 2014, p. 30). Esto implica que la reforma indígena aprobada por el Congreso tiene efectos para el resto de las comunidades indígenas en el estado, excepto para Cherán, pero también resolvió que este municipio debe ser consultado para cualquier reforma en materia de derechos indígenas.

El reconocimiento legal de las nuevas estructuras de Gobierno no es suficiente por sí solo: requiere principalmente la aprobación y el respaldo de los cheranenses, esto 
es, de legitimidad comunal. Una oportunidad para evaluar esta nueva forma de Gobierno y decidir sobre su continuidad fue la renovación del segundo Concejo Mayor del Gobierno Comunal, celebrada en mayo de 2015, durante la cual la mayoría decidió seguir ensayando estas formas de nombramiento y de Gobierno, aunque también hubo quienes intentaron regresar al sistema partidario: un grupo de comuneros inconformes solicitó formalmente al IEM la organización de una consulta para preguntar nuevamente si la próxima elección de sus autoridades municipales sería a través de usos y costumbres o por el sistema partidario. En diciembre de 2014, el Consejo General del IEM respondió que la solicitud no procedía, en virtud de que no existían elementos que lesionaran los derechos de participación de los demandantes. Los promoventes interpusieron un juicio ante el TEPJF, el cual determinó a su vez que la demanda era improcedente por no haber agotado los medios de impugnación local, esto es, el Tribunal Electoral del Estado de Michoacán (TEEM). Esta autoridad electoral local ordenó el envío de la solicitud al Concejo Mayor de Gobierno Comunal, para efecto de que analizara y resolviera lo que en derecho correspondiera. El Concejo Mayor resolvió declarar improcedente la solicitud presentada.

Entonces, el grupo de cheranenses inconforme promovió nuevamente un juicio ante el TEPJF porque consideró lesionados sus derechos de participación política. Dicha autoridad electoral resolvió que el TEEM determinó indebidamente que el Concejo Mayor del Gobierno Comunal de Cherán fuera el órgano competente para dar respuesta a la petición. No obstante, la nueva resolución del TEPJF reconoció la legitimidad de las asambleas de barrios que se celebraron ante la demanda y en las que se acordó nuevamente mantener el sistema normativo para el nombramiento de sus autoridades municipales (Tribunal Electoral del Poder Judicial de la Federación, 2015). De este modo, bajo dicho 
sistema se dio el nombramiento del segundo Concejo Mayor del Gobierno Comunal, en concreto el 3 de mayo de 2015, con la asistencia de 4086 comuneros provenientes de los cuatro barrios (Periódico Oficial del Gobierno Constitucional del Estado de Michoacán de Ocampo, 2015).

La sentencia de la SCJN y las resoluciones del TEPJF han dado respaldo legal a la estructura de Gobierno. Sin embargo, la legitimidad debe ser resultado del desempeño de dicha estructura, de la valoración que le hagan sus miembros, quienes a pesar de los posibles desaciertos de sus autoridades decidieron volver a ensayar con estas instancias para llevar a cabo la toma de decisiones y el ejercicio de su Gobierno.

Ahora bien, esto no resuelve de fondo las tensiones latentes entre quienes quieren seguir apostando por esta vía y quienes prefieren regresar al sistema partidario. Se puede señalar que esta discrepancia es resultado de la eficacia de las relaciones clientelares partidistas, lo cual en parte es cierto, pero tampoco es una explicación única del disenso. Los procesos son más complejos: se trata de un desafío a los contenidos y prácticas democráticas que remite de nuevo al debate sobre la convivencia de derechos individuales y derechos colectivos, entre la primacía de la mayoría y la voz de quienes por ahora son minoría.

Este hecho reta a la construcción de la democracia y a redefinir sus contenidos; se trata de una democracia comunitaria que reclama a la sociedad mayor su reconocimiento, la no discriminación y su inclusión. Por tanto, estos discursos deben ser coherentes con las prácticas al interior de estos espacios comunales. Son principios democráticos que debieran regir la vida colectiva no sólo de las comunidades indígenas, en las que los críticos suelen centrar su atención, sino de todos los ámbitos de representación y Gobierno y de la vida política de la sociedad en general. 
La organización social sustentada en las reuniones de fogata, asambleas de barrio y asamblea comunal, además de una serie de consejos ${ }^{2}$ cuyos miembros son nombrados de manera proporcional por los barrios, contribuye a una participación de un número importante de comuneros en la deliberación, construcción de consensos y definición del proyecto de comunidad, no libre de tensiones y contradicciones. Además, los espacios que la componen son de vigilancia y sanción comunal del desempeño de cada una de las instancias de la estructura de Gobierno comunal, lo que ha llevado a la destitución de algunos de sus integrantes.

La creación de algunas empresas comunales, como el vivero, el aserradero o las minas (grava y fabricación de adoquines), y las fuentes de empleo temporal, como la reforestación, han ayudado a dar respuesta a las necesidades de ingreso de los comuneros desempleados, algunos de ellos extalamontes, y sin acceso a la tierra. La rotación de los empleos por barrio redistribuye, hasta ahora, los insuficientes recursos económicos.

La generación de fuentes de empleo es uno de los principales retos para quienes gobiernan la comunidad. Se busca que el corte clandestino de sus bosques no sea la única opción de ingresos que tenga un sector de comuneros y que el crimen organizado no encuentre condiciones para su retorno. Recientemente, incluso, la comunidad fue premiada por su labor de reforestación, ${ }^{3}$ de la cual sus miembros se

2. Se crearon seis consejos: Coordinador de los Barrios, Bienes Comunales, Administración Local, Asuntos Civiles, Vigilancia y Procuración de Justicia y de Programas Sociales, Económicos y Culturales. Posteriormente, se conformaron dos más, el de mujeres y el de jóvenes. Junto con los miembros del Concejo Mayor y los integrantes de la Ronda Comunitaria, se encuentran en la estructura de Gobierno alrededor de doscientos cincuenta comuneros.

3. Representantes de comunidades michoacanas de Cherán y Patambán recibieron el premio Energy Globe Award 2016 por su proyecto Ejido Verde y Resinado, enfocado en la conservación de recursos naturales. El galardón es la distinción más importante que se entrega anualmente a los mejores proyectos nacionales y globales en materia de energías (20 minutos, 2016). 
sienten orgullosos porque los bosques les son esenciales, esto es, forman parte de lo que consideran su territorio comunal -debe recordarse que la defensa de los bosques fue uno de los motivos por los cuales varios comuneros se sumaron a las acciones en pro de la seguridad en el municipio-.

No obstante, este creciente número de comuneros sin tierra es un punto pendiente en la agenda de la comunidad y un desafío para la consolidación del Gobierno comunal. No debe olvidarse que la distribución de los bienes naturales, su aprovechamiento y control han sido el centro de las disputas entre las luchas de facciones y el hilo que ha tejido, en gran parte, la historia política de la comunidad (Calderón, 2004). Aunque esta problemática no es exclusiva de Cherán, sino de la mayoría de los núcleos agrarios, la presión sobre la tierra en dicha comunidad va en aumento y las válvulas de escape no son siempre la migración, la multiactividad u otras fuentes de ingresos lícitas. Sería un gran paso cualitativo para la comunidad ir del ejercicio de los derechos políticos como colectividad a la construcción de un Gobierno comunal con redistribución de recursos y bienes.

Revisemos el caso de San Francisco Pichátaro. Esta comunidad se ha destacado por su participación política, como muchas otras. Dicha comunidad participó en la alternancia partidaria en el Ayuntamiento de Tingambato, e incluso varios de sus miembros formaron parte del Gobierno municipal. Algunos de los dirigentes de la anterior Organización Nación Purépecha (ONP), luego ONP-Zapatista, son originarios de esta comunidad. La apuesta de parte de muchos de sus comuneros en la competencia partidaria, así como su militancia perredista, también entraron en crisis, y después de seis administraciones perredistas (1990-2007), el PRI regresó al ayuntamiento en el periodo 2008-2011, aunque el PRD lo recuperó en la siguiente gestión (2012-2015) y lo mantiene en la actual administración (2015-2018). 
Para el proceso electoral de 2015, la asamblea comunal acordó "que no se permitiría la instalación de las casillas [...], anteponiendo que hay desencanto por parte de los habitantes de la comunidad hacia los diferentes partidos políticos y que han decidido nombrar a sus autoridades por el sistema de usos y costumbres" (Tribunal Electoral del Estado de Michoacán, 2015, p. 8). Para el ejercicio de este derecho, los miembros de la comunidad presentaron la solicitud formalmente al IEM, cuyo Consejo Distrital acordó aprobarla y hacer los ajustes de ubicación de casillas electorales para la votación sobre el proceso electoral federal.

La comunidad de Pichátaro también participó en varios de los Encuentros Indígenas, de los cuales posteriormente surgió el denominado Consejo Supremo Indígena de Michoacán (CSIM). Como ya se dijo, una de las demandas que unifica a un número importante de comunidades p’urhépechas es que el ayuntamiento les entregue la parte proporcional del presupuesto municipal para que sea administrado por las autoridades comunales. Esta es la principal reivindicación que sostiene actualmente la comunidad de Pichátaro, apoyada por el CSIM (Cambio de Michoacán, 2015). Tras varias reuniones con la representación municipal (2012-2015), se acordó la entrega de recursos a la comunidad. Sin embargo, el entonces presidente municipal entrante se negó a cumplir con los acuerdos, argumentando que

El artículo I I 5 en nuestra carta magna señala en su fracción IV que los municipios administrarán libremente su hacienda, la cual se formará de los rendimientos de los bienes que les pertenezcan, así como de las contribuciones y otros ingresos que las legislaturas establezcan a su favor, los recursos serán ejercidos directamente por los Ayuntamientos [,] y las Legislaturas de los estados serán quienes revisarán y fiscalizarán las cuentas públicas municipales (Monreal, 2016a). 
Una vez agotada la vía de la negociación, la comunidad emprendió el camino jurídico. Por medio de un colectivo de abogados, que son los asesores legales de Cherán, en septiembre de 2015 interpuso un recurso ante el TEPJF para reclamar su derecho a administrar la parte proporcional de los recursos municipales.

En mayo de 2016, el TEPJF resolvió que la comunidad contaba con el derecho "[...] a participar efectivamente en los procesos de toma de decisiones que puedan afectar sus derechos a la autodeterminación, autonomía y autogobierno, así como en aquellas que les permitan determinar libremente su condición política y perseguir libremente su desarrollo económico, social y cultural" (Tribunal Electoral del Poder Judicial de la Federación, 2016a, p. 137).

Asimismo, el TEPJF ordenó la realización de una consulta a la comunidad "por conducto de sus autoridades tradicionales" (Tribunal Electoral del Poder Judicial de la Federación, 2016a, p. 133), para determinar la administración de los recursos municipales correspondientes. También vinculó al IEM para que en colaboración con las autoridades municipales y comunales organizara dicha consulta. En caso de que los resultados de la consulta fueran favorables, se conminó al ayuntamiento a acatar la decisión.

Posterior a esta resolución, la denominada Comisión de Enlace de Pichátaro ${ }^{4}$ entregó al IEM documentos en los que informó: 1) que la autoridad tradicional es el Concejo Comunal, en sustitución del jefe de tenencia; 2) sobre el nombramiento de los representantes de los siete barrios; y 3) un acta en la que el recién integrado Concejo Comunal otorgaba un nombramiento a la Comisión de Enlace para que se encargara de organizar, junto con el IEM, la consulta 
previa, libre e informada (Periódico Oficial del Gobierno Constitucional del Estado de Michoacán, 2016).

La Comisión de Enlace y los funcionarios electorales acordaron el calendario y los detalles de todo el proceso. El 25 de junio de 2016, se efectuó la fase informativa previa a la realización de la consulta por parte del consejero presidente de la Comisión Electoral para la Atención a Pueblos Indígenas del IEM, a la que asistieron únicamente los siete integrantes del Concejo Comunal, cuatro miembros del Comisariado de Bienes Comunales y los siete representantes de los barrios. Por ello, días después, un grupo de comuneros solicitó al IEM que "se debe abrir e informar a toda la comunidad el proceso de consulta que se realiza en la referida comunidad [...] consideran violatorio de sus derechos que sólo dieciocho personas decidan en la comunidad" (Periódico Oficial del Gobierno Constitucional del Estado de Michoacán, 2016, p. 14). La respuesta del IEM fue que se estaban respetando los derechos reconocidos en los instrumentos internacionales en materia indígena, "en los cuales se sustenta que la consulta se lleve a cabo a través de las autoridades tradicionales y representativas" (Periódico Oficial del Gobierno Constitucional del Estado de Michoacán, 2016, p. 14).

La consulta se efectúo el 4 de julio del mismo año, y sus trabajos consistieron en formular las siguientes preguntas: 1) ¿Están de acuerdo en la transferencia de los recursos y responsabilidades respecto a su derecho a la administración directa de los recursos económicos que les corresponden, con base en su derecho a la libre determinación?; y 2) ¿Qué autoridad será la responsable de la administración de los recursos públicos que les corresponden?

Los comuneros consultados fueron los mismos que participaron en la fase informativa, quienes manifestaron estar de acuerdo en que se transfirieran los recursos y que la autoridad responsable de su administración fuera el Concejo Comunal. La consulta fue declarada válida por el 
IEM el 5 de julio de 2016. Posteriormente, un grupo de ocho comuneros de Pichátaro promovió un juicio ante el TEPJF en contra de la validez de la consulta. Argumentaron que esta debió cumplir con los principios establecidos en el marco jurídico internacional:

5) Democrático: en la consulta se deben establecer los mecanismos correspondientes a efecto que pueda participar el mayor número de integrantes de la comunidad; que en la adopción de las resoluciones se aplique el criterio de mayoría y se respeten en todo momento los derechos humanos. 6) Equitativo: debe beneficiar por igual a todos los miembros, sin discriminación, y contribuir a reducir desigualdades, garantizando la participación de las mujeres en condiciones de equidad frente a los varones [...]. Por todo lo anterior, es claro que el acuerdo aprobado por el Consejo General del Instituto Electoral de Michoacán, en la [sic] que califica y declara la validez de la consulta indígena en la comunidad de San Francisco Pichátaro, Municipio de Tingambato, Michoacán, carece de todo valor jurídico [...] pues como ya se sabe, en dicha consulta se excluyó a la comunidad de participar en la consulta previa e informada, a la comunidad relacionada con la transferencia de responsabilidades respecto a su derecho (Tribunal Electoral del Poder Judicial de la Federación, 2016b, p. 13).

El TEPJF resolvió que el juicio era improcedente y que debía reencauzarse vía inejecución de sentencia. También se presentó otro juicio por parte de comuneros, quienes posteriormente desistieron argumentando que fueron engañados por personal del ayuntamiento que les pidió copia de su credencial para la realización de mejoras en sus hogares. Sobre esto se presentaron varios testimonios:

Yo también fui engañada, las mismas personas fueron a mi casa para que les diera los datos porque iban a hacernos un baño [,] y yo les dije que no, porque no tenía suficiente agua para ponerlo y me contes- 
taron que no se requería porque el municipio nos podría [sic] todo lo necesario, y yo les di la copia de la credencial (Agabo, 2016).

Sobre la consulta, cabe señalar que, en el caso de Cherán, tanto la fase informativa como la propia consulta fueron abiertas a todos los comuneros de cada uno de los cuatro barrios, y la asistencia total al proceso fue de 2 307. Además, la fase informativa estuvo a cargo de académicos, mientras que la consulta la organizaron los propios comuneros en presencia de los funcionarios electorales, quienes dieron validez al proceso; previamente hubo un trabajo de discusión y deliberación en cada uno de los cuatro barrios. Los resultados de la consulta en Cherán fueron de 4846 comuneros a favor de los usos y costumbres y ocho en contra (Ventura, 2012, p. 169).

En agosto de 2016, el Ayuntamiento de Tingambato informó al IEM que no tenía inconveniente en cumplir la sentencia, "siempre que previamente se celebre una asamblea general comunitaria que lo determine, y dicho presupuesto sea etiquetado y fiscalizado por el Congreso del Estado, así como ministrado u otorgado directamente por el Gobierno del estado de Michoacán" (Tribunal Electoral del Poder Judicial de la Federación, 2016c, p. 6).

De inmediato, las autoridades tradicionales de Pichátaro impugnaron por medio de un juicio ciudadano las determinaciones del ayuntamiento, de nuevo ante el TEPJF, instancia que resolvió a favor de la comunidad. Además, señaló que la resolución debería ser cumplida en todos sus términos, tanto por el ayuntamiento como por el Congreso del Estado. También, el TEPJF especificó que "se encuentra facultado para hacer uso de los medios de apremio necesarios para hacer cumplir de manera expedita sus sentencias y resoluciones" (Tribunal Electoral del Poder Judicial de la Federación, 2016c, p. 9). 
A pesar de esta advertencia, el ayuntamiento continuó negándose a entregar los recursos, no sin antes dejar de otorgar los servicios de luz y limpieza a la comunidad, como una medida de presión. Después de estos recursos jurídicos, y tras el señalamiento por parte de las autoridades comunales de que en caso de continuar negándose a acatar la sentencia solicitarían la destitución del presidente municipal, el ayuntamiento decidió entregar los recursos municipales correspondientes a la administración restante del 2016 a los miembros del Concejo Comunal:

[...] el 28 por ciento del ramo 28 correspondiente a las participaciones a entidades federativas y municipios, y del Fondo IV de Aportaciones para el Fortalecimiento de los Municipios [...]; y el 35.5 por ciento del Fondo III de Aportaciones para la Infraestructura Social Estatal y Municipal. Asimismo[,] se convino que a partir de 2017 sería el 35.5 por ciento de los tres rubros lo que se destin[aría] a Pichátaro (Monreal, 2016b).

No obstante, la disidencia al interior de la comunidad sigue presente. Por ejemplo, un comunero declaró en el Congreso del estado que el desacuerdo no es porque les den los recursos:

[...] nosotros no nos oponíamos al proceso, que llegara el recurso oficial, pero únicamente no queríamos a la gente que está ahí, sino que el pueblo que decidiera [sic], así como se pone un jefe de tenencia, como se pone un representante, lo ponemos en la pérgola, en la plaza, y ahí nos formamos a ver quién, y [decimos] "este sí, este no". Lo que no queremos [que pasara] ahí [en el proceso], porque hay pura, pues, gente vividora [...],y pura gente que no está dentro de las comunidades. Entonces, ya [a] la comunidad no se le tomó en cuenta, a los comuneros. $\mathrm{Ni}$ a los barrios, ni nada [...]. Únicamente ellos, ellos en la consulta, la primera, la resolución decía que iba a hacerse en el interior, como lo 
dice aquí: "hombres y mujeres", y que abierto [...], son gente que no toma en cuenta a lo que es pueblo (nota en diario de campo, 2016e). ${ }^{5}$

Como se puede apreciar, el desafío que enfrenta la comunidad no es menor: la disputa por los recursos puede convertirse en un nuevo escenario de confrontación de las luchas de facciones. Es importante que los integrantes de la nueva forma de Gobierno demuestren un buen ejercicio de los recursos, ${ }^{6}$ en correspondencia con los acuerdos de la asamblea, y que entreguen cuentas claras a sus miembros. No obstante, su legitimidad dependerá no sólo de una buena administración, sino de la tarea impostergable de dirimir las diferencias internas ${ }^{7} \mathrm{y}$ de su capacidad para construir los consensos necesarios para que la vida colectiva haga posible esta nueva manera de pensarse como comunidad.

\section{El Consejo Supremo Indígena de Michoacán: una expresión del movimiento indígena}

El CSIM nació formalmente en agosto de 2015, en la comunidad de Caltzontzin, municipio de Uruapan, como resultado de una serie de foros que se realizaron en distintas comunidades indígenas de la Meseta P'urhépecha a lo

5. La información completa de referencia sobre las notas de diario de campo fue incluida en la bibliografía del presente artículo por los apellidos de la autora del mismo, al igual que se hace con las entrevistas.

6. "Armando Cortés Vargas, representante legal de Pichátaro, aseguró que el recurso correspondiente a dicha comunidad de Tingambato será de cerca de tres millones de pesos en lo que corresponde al último trimestre de 2017 [sic] [...],ya que de un millón de pesos que le correspondía al año [,] se presume [que] subirá hasta doce millones, por lo que podrá ponerse en marcha el plan de desarrollo para la comunidad" (Ramírez, 2016).

7. A decir del diputado perredista Ángel Cedillo, presidente de la Comisión de Pueblos Indígenas, existían hasta hace dos años varias denuncias en contra de los miembros del Concejo Comunal por parte de algunos comuneros, quienes los acusaban de realizar actos violentos contra los que no estaban de acuerdo con este nuevo proyecto de la comunidad; a su decir, había ocho denuncias penales. Sin embargo, ningún miembro del concejo había recibido alguna notificación al respecto (Hernández, 2016). 
largo de poco más de dos años. El primer foro, denominado Encuentro Estatal Indígena, tuvo lugar en la comunidad de Urapicho el 16 de marzo de 2013, y su orden del día se centró en la discusión sobre seguridad y justicia, con miras a la posible conformación de una ronda comunal regional.

La convocatoria formal al encuentro la promovió el entonces presidente de la Comisión de Pueblos Indígenas del Congreso del Estado, el diputado perredista Eleazar Aparicio, pero también se realizó por invitación del Concejo Mayor del Gobierno comunal de Cherán, que no quiso aparecer como principal promotor de esta reunión. El encuentro se realizó en el contexto del surgimiento de las llamadas autodefensas (febrero de 2013), en varias partes del estado, en respuesta a la grave situación de violencia ocasionada por las acciones del crimen organizado. La iniciativa de crear una ronda regional comunal se diluyó, aunque sí se formaron rondas en algunas comunidades, como Urapicho.

El segundo encuentro se efectuó más de un año después, en diciembre de 2014, en la comunidad de Uricho, municipio de Pátzcuaro, en el marco del inicio del proceso electoral para renovar la gubernatura, el Congreso local y las presidencias municipales. Este encuentro y los siguientes fueron organizados únicamente a iniciativa del diputado Eleazar Aparicio (2012-2015) y su asesor Pavel Guzmán. ${ }^{8}$ Los temas que se abordaron en estos encuentros fueron cambiando su centro de atención de acuerdo con las coyunturas electorales y políticas de la entidad: iniciaron con la formulación de una iniciativa de ley en materia indígena; después, se centraron en el reconocimiento de los jueces de tenencia, que habían desaparecido por una reforma en materia judicial en 2005; posteriormente, en el derecho a la consulta; luego, en contra

8. Pavel Guzmán es historiador. Cuatro de sus tíos y su abuelo fueron víctimas de desaparición forzada en la década de los setentas del siglo pasado, cuando militaron en el Movimiento de Acción Revolucionaria (MAR). Actualmente, Pavel milita en el Frente Popular Emiliano Zapata, en Pátzcuaro, y es miembro activo del CSIM.

\section{6}


de la posible desaparición de la Secretaría de Pueblos Indígenas (SPI); y finalmente, en la asignación directa por parte de los ayuntamientos de los presupuestos municipales a las comunidades indígenas, lo que se ha denominado presupuesto directo.

En total, fueron nueve encuentros. El último se celebró en agosto de 2015, del cual nació el CSIM. La integración de comunidades en el CSIM es dinámica, pero se puede señalar que son alrededor de treinta, entre ellas Santa Fe de la Laguna, Naranja de Tapia, Urapicho, Caltzontzin, Pichátaro, Zirahuén, Sevina, Capacuaro, Tiríndaro, Angahuan, Uricho, Turícuaro, Pamatácuaro, San Ángel Zurumucapio, Zopoco, Cuanajo, Comachuén, Cocucho, Santa Cruz Tanaco, San Felipe de los Herreros, Sicuicho, Cherato, Cheratillo, Oruscato, 18 de Marzo, Apo del Rosario, San Lorenzo, Tacuro y las llamadas Comunidades del Sur.

El presupuesto directo se ha constituido en la principal demanda de las comunidades indígenas. Pavel Guzmán realizó un recorrido por varias comunidades para informar sobre este derecho y para promover reuniones con los ayuntamientos sobre el tema. La participación de este asesor ha sido fundamental en el proceso de constitución del CSIM y en la definición de esta demanda como central en el conjunto de reivindicaciones indígenas de la organización. La demanda no es nueva: algunas comunidades lo habían solicitado sin lograr acuerdos concretos, pero al integrarse orgánicamente en el CSIM esta demanda adquirió mayor relevancia formando parte de la agenda comunitaria inmediata en las negociaciones con los nuevos ayuntamientos.

Pavel Guzmán señaló por medio de un comunicado la existencia de un trato discriminatorio hacia los pueblos originarios en la distribución del presupuesto por parte del Gobierno estatal, y declaró a la prensa que para el ejercicio de 2016 la SPI había destinado 
[...] la cantidad de MXN 103627453.00 [...], [que] agrupa también recursos federales [...], lo que significa que el presupuesto también es engañoso, pues pretende dar la falsa impresión de que se destinan más recursos de los que realmente son, pues la mayoría del capital, alrededor de setenta y seis millones, son aportados por la Federación; en contraparte, el estado aporta realmente 27 millones, de los cuales veinte millones derrocha en gasto corriente [...], al final sólo quedan un poco más de 7.5 millones para atender a los pueblos originarios de Michoacán [...] (Quadratín, 2016a).

El CSIM también ha realizado algunas acciones con la intención de presionar al Gobierno del estado para que dé respuesta satisfactoria a sus demandas. Esta estrategia política le ha permitido tener una serie de reuniones con el secretario de Gobierno a las que acuden titulares de diferentes agencias estatales para atender demandas específicas de las comunidades. También, el CSIM se ha sumado a las movilizaciones en apoyo a normalistas y maestros, las cuales fueron particularmente significativas durante el año de 2016.

El principal logro del CSIM es el acuerdo con varios presidentes municipales que han cedido a la petición del presupuesto directo, obligados por la presión o por su propio cálculo político, aunque no sin antes intentar acciones de disuasión entre las comunidades, como la dilación en el seguimiento de las reuniones, argumentos de crisis financiera y asegurar que no están obligados en virtud de que no es un derecho reconocido en la constitución.

También, los munícipes han buscado arreglos entre ciertos grupos al interior de las comunidades para que la demanda respecto al presupuesto directo no prospere en las asambleas. Por ejemplo, en 2016, el entonces juez de tenencia de la comunidad de Comachuén comentó que su asamblea no respaldó esta demanda porque miembros de la misma manifestaron que no estaban de acuerdo bajo el argumento de que se corría el riesgo de perder los apoyos 
de los programas gubernamentales, y que así les había sido señalado por el presidente municipal (entrevista personal, 2016a).

Los municipios en los que se ha discutido el tema son Quiroga, Ziracuaretiro, Uruapan, Salvador Escalante y Pátzcuaro. Los avances son distintos en cada uno de ellos, pero principalmente se han destinado a las comunidades recursos del Fondo de Obras (entrevista personal, 2016h). Esta demanda del presupuesto directo también ha encontrado eco en otras regiones indígenas del estado, como la del oriente. Algunas comunidades mazahuas y otomíes así lo manifestaron al diputado perredista Juan Figueroa Gómez, quien a partir del 29 de septiembre de 2016 figura como el presidente de la Comisión de Pueblos Indígenas en el Congreso:

Durante el encuentro en el que estuvieron presentes encargados del orden, jefes de tenencia, representantes de bienes comunales y comisariados ejidales, el legislador escuchó las demandas de los hermanos de los pueblos originarios de dicha región, con quienes se comprometió a resolver sus planteamientos y llevarlos ante las instancias. Entre los temas que se abordaron destaca el presupuesto participativo (Cambio de Michoacán, 2016).

Por lo pronto, también la comunidad de San Felipe de los Herreros, del municipio de Charapan, ha recurrido al TEPJF para reclamar este derecho, recurso que se encuentra en proceso. Asimismo, otras comunidades se están organizando para exigir, vía la judicialización de sus derechos, la entrega de recursos municipales. 
4. Derechos políticos y consulta. Derechos coartados, a destiempo, y disputa institucional

El que fuera presidente de la Comisión de Pueblos Indígenas, el diputado perredista Ángel Cedillo (septiembre de 2015 a 28 de septiembre 2016), presentó una serie de iniciativas en materia indígena: la Ley de Consulta a las Comunidades y Pueblos Originarios, la reforma al Código Electoral, la Ley de Derechos Lingüísticos y la Ley de Fomento Artesanal. ${ }^{9}$

Después de realizar algunos foros en la costa y el oriente, pero no así en la región p’urhépecha bajo el argumento de que no había condiciones debido a la efervescencia del movimiento de los estudiantes normalistas y del magisterio, se organizó un evento denominado Foro de Consulta y Procesos Legislativos sobre los Derechos de los Pueblos Originarios en el Congreso del Estado, el 10 de septiembre de 2016.

A este foro acudieron varios representantes de comunidades, principalmente de la Meseta P'urhépecha, entre ellos miembros de las comunidades de Cherán y Pichátaro, quienes irrumpieron al inicio del evento para manifestar su total desacuerdo con tales iniciativas por no haber sido consultados al respecto y para denunciar que dicho foro no cumplía con los estándares señalados por la legislación internacional para que fuese considerado como una consulta. En consecuencia, denunciaron:

Los foros no son una consulta, son una simulación dado que no son los pueblos y comunidades indígenas los que han decidido este procedimiento [...] la SCJN [...] en la sentencia [...] nos dio la razón al señalar que el Congreso del Estado está obligado a consultarnos de acuerdo a nuestros usos y costumbres [...] (nota en diario de campo, 2016d). 
La iniciativa de ley sobre la consulta se sustenta jurídicamente en el marco internacional, pues considera en su artículo 2 que la consulta debe efectuarse "respetando los principios y valores que fundamentan los sistemas normativos internos de las comunidades y pueblos originarios bajo el régimen de 'usos y costumbres', agregando que sus resultados tendrán efectos vinculatorios" (Gaceta Parlamentaria, 2016a, p. 3).

Por tanto, se retoma el requerimiento del consentimiento libre, previo e informado, con carácter vinculatorio, para medidas administrativas, diseño de planes de desarrollo, iniciativas de ley, ejecución de obras, expropiación de tierras en núcleos agrarios, cambios en las modalidades de las tierras, autorizaciones y permisos para el aprovechamiento de los recursos biológicos y genéticos, instalación de depósitos de residuos peligrosos, entre otros actos, pero en su artículo 12 dicha iniciativa señala que tal efecto vinculatorio no procederá "tratándose de la programación de los presupuestos de ingresos y egresos, recaudación tributaria y obligaciones fiscales y municipales" (Gaceta Parlamentaria, 2016a, p. 5). Como se puede observar, la iniciativa de ley sobre la consulta integra gran parte de lo que ya se reconoce en el marco jurídico internacional, pero es incoherente con su propio contenido pues no fue elaborada como resultado de una consulta, además de que tiene especial interés en coartar el derecho sobre el presupuesto directo, es decir, es una iniciativa cuyo diseño está pensado para inhibir este reclamo.

Respecto a la reforma al Código Electoral propuesta por el diputado Cedillo, esta contempla incluir a los indígenas en la contienda electoral: "Los partidos políticos están obligados a garantizar la participación de los pueblos y comunidades indígenas, integrando un candidato dentro de los tres primeros números, que cuente con calidad reconocida como tal" (Gaceta Parlamentaria, 2016b, p. 6). 
Esta reforma pretende responder al reclamo que hicieron los miembros de las comunidades años atrás, respecto a su derecho a ocupar los cargos de representación, aunque atiende únicamente dicho derecho para la integración del Poder Legislativo local. Por tanto, no responde del todo a la demanda, y además llega tarde frente al gran desencanto del sistema partidario que se extiende en las regiones indígenas del estado: el nombramiento de las autoridades por usos y costumbres y la no instalación de las casillas, sin duda, son mecanismos que cuestionan y debilitan el monopolio de los partidos políticos como únicas instancias de participación política. Ante la propuesta de la creación de un posible distrito electoral indígena, el diputado Ángel Cedillo mencionó de manera enfática que no procedía porque "íbamos a pisotear el derecho político-electoral de los individuos" (entrevista personal, 2016c).

Por su parte, el IEM, que ha participado activamente en los procesos de consulta en las comunidades de Cherán, Santa Cruz Tanaco y Pichátaro, también se dio a la tarea de organizar una serie de foros para elaborar la propuesta de lo que llamó Reglamento de Consulta a Pueblos y Comunidades Indigenas del Estado, acordada en su sesión del 20 de abril de 2016 (Instituto Electoral de Michoacán, 2016a). El consejero presidente sostuvo entonces que

El IEM tiene la obligación de fijar las reglas de cooperación de comunidades o grupos indígenas, actualmente no existe una ley que regule estas formas de cooperación, por lo que nosotros tenemos la obligación de generar estos mecanismos para garantizar que las comunidades puedan involucrarse bajo los esquemas de participación (Quadratín, 2016b).

El IEM ha organizado varios foros: para el oriente, en la comunidad de San Felipe de los Alzati (el 3 de mayo de 2016) y otro en Ciudad Hidalgo; y para los p’urhépechas, en Santa Cruz Tanaco (19 de mayo de 2016) y en el municipio de Chilchota 
(23 de octubre de 2016) (Instituto Electoral de Michoacán, 2016b). A decir del instituto, la propuesta de reglamento ha sido aprobada por los asistentes a dichos foros, aunque la costa nahua aún no ha sido consultada, ni muchas otras comunidades. Cherán, por su parte, manifestó su rechazo a esta iniciativa.

El reglamento pretende regular los procesos de elección de sistemas normativos internos bajo la organización y supervisión del IEM, además, se propone elaborar un catálogo de los pueblos y comunidades indígenas en el estado. La propuesta del diputado Cedillo, por su parte, delega la atribución de la organización de consultas a la SPI, de modo que hay una disputa velada entre el IEM y el Poder Legislativo por definir la competencia de la organización de las consultas y las atribuciones para elaborar una legislación que regule estos mismos procesos.

\section{Desafíos}

Las distintas respuestas comunitarias, vía de facto $\mathrm{y}$ de jure, develan las tensiones aún no resueltas entre una ciudadanía individual y una ciudadanía colectiva, como cimientos de un Estado nación cada vez más fragmentado, heterogéneo y contradictorio. Sin duda, hay un avance sustancial por parte de las instancias judiciales en la atención de los asuntos de las comunidades indígenas, "lo que contrasta con lo que sucedía hasta hace apenas unos años cuando la visión liberal, monojurídica, impedía abrirse a reconocer los derechos colectivos en el proceso judicial" (Sierra, 2014, p. 2).

El Poder Judicial se ha convertido en un poder efectivo, cuyas sentencias tienen trascendencia en la vida de los pueblos indígenas, principalmente en materia electoral, y ahora también en asuntos de distribución de recursos municipales, por lo menos en Michoacán. Sin embargo, la justiciabilidad 
de los derechos debería ser sólo una etapa de transición, esto es, no debería ser necesario acudir a dichas instancias para exigir el respeto a los derechos reconocidos, sino que los representantes y funcionarios de los diferentes ámbitos de Gobierno, el Poder Legislativo, y las instituciones electorales y políticas, entre otros, deberían respetar esos derechos sin que una sentencia los obligue a ello. Como bien afirmó Rodolfo Stavenhagen, aún falta mucho camino para cerrar la brecha "entre la legislación y la práctica administrativa, jurídica y política” (Stavenhagen, 2008, p. 130).

También, estos procesos develan las tensiones intracomunitarias y las luchas entre facciones, que una sentencia puede resolver jurídica pero no socialmente. Estas tensiones son competencia exclusiva de los miembros de las comunidades. Las instancias judiciales son un nuevo espacio en el que se apoyan las facciones comunales para tratar de acotar el campo de acción de los disidentes. Como bien sostiene Teresa Sierra, la revisión de varios expedientes judiciales sobre conflictos electorales da cuenta de

$[\ldots]$ las disputas por el poder local [...] lo que significa también disputar el contenido de los usos y costumbres.Varios de los expedientes revelan una serie de conflictividades que rebasan el proceso mismo electoral y dan cuenta de un tejido social confrontado [...]. No es la competencia de las autoridades electorales locales y federales dirimir este tipo de conflictos, pero sí tienen la responsabilidad de propiciar la certidumbre que faciliten los acuerdos locales (Sierra, 2014, p. 19).

Al parecer, se está frente a una etapa en la que también los derechos indígenas son el centro de una disputa para definir sus contenidos y su interpretación entre representantes de las instancias judiciales, legisladores, funcionarios electorales, representantes del poder municipal, pero también al interior de las comunidades y organizaciones étnicas. Los conflictos internos no podrán resolverse por 
la vía jurídica: la manera de deliberar sobre ellos, sus instancias y sus mecanismos son tareas de los miembros de las comunidades y organizaciones, por lo que su solución depende de su cohesión social y de su capacidad para construir consensos. De otro modo, se estaría abriendo la puerta a las instancias estatales para incidir en la vida interna de las comunidades, y los efectos de dicha intromisión pueden ser contraproducentes.

Para terminar, la vía de facto da muestra de un tejido comunitario que hace posible el ejercicio de derechos, como un cuarto ámbito de Gobierno, que deja fuera la necesidad de recurrir a instancias judiciales y la espera de una legislación que los reconozca, lo cual no quiere decir que no sea fundamental que queden contemplados en una legislación. Esta es una de las preocupaciones de los legisladores frente a la demanda del presupuesto directo, es decir, que haya cada vez más comunidades que tengan en su control dicho presupuesto, nombren a sus autoridades al margen de los partidos políticos y no permitan la instalación de las casillas electorales. En ese sentido, la tarea de cerrar la brecha debe contemplar ambas vías, la de facto y la de jure, de modo que la legitimidad sea condición para que la comunidad deje de ser un ideal abstracto. $€$

20 minutos (27 de julio de 2016). "Proyecto purépecha Bibliografía gana galardón Energy Globe Award”. Recuperado de: http://www.20minutos.com.mx/noticia/ I 17019/0/proyecto-purepecha-gana-galardon-energy-globe-award2016/\#xtor=AD- $\mid \& x t s=513356$

Agabo, B. (02 de agosto de 2016). "Denuncian comuneros de Pichátaro engaño para sustentar impugnaciones en consulta del IEM". Cambio de Michoacán. Recuperado de: http://www.cambiodemichoacan.com.mx/nota-n8506 Bengoa, J. (2000). La emergencia indígena en América Latina. Santiago de Chile: Fondo de Cultura Económica. 
Calderón Mólgora, M. A. (2004). Historias, procesos políticos y cardenismos: Cherán y la Sierra P'urhépecha. Zamora: El Colegio de Michoacán.

Cambio de Michoacán (25 de septiembre de 2015)."Comuneros causan destrozos y queman documentos en alcaldía de Tingambato". Recuperado de: http://www. cambiodemichoacan.com.mx/nota-265099

Cambio de Michoacán ( 10 de diciembre de 2016). “Otomíes y mazahuas demandan presupuesto participativo: Juan Figueroa". Recuperado de: http://www.cambiodemichoacan.com.mx/nota-n I 5044

Domingo, P. (2007).“'La judicialización de la política: el nuevo perfil de la Suprema Corte en el sistema político de México", en J. M. Palacio, y M. Candioti (comps.), Justicia, política y derechos en América Latina (pp. 27-44). Buenos Aires: Prometeo.

Gaceta Parlamentaria (II de mayo de 2016a). "Iniciativa de decreto mediante la cual se crea la Ley de Consulta a las Comunidades y Pueblos Originarios del Estado de Michoacán de Ocampo", p. 7.

Gaceta Parlamentaria (09 de junio de 2016b). “Iniciativa de decreto mediante la cual se reforma el artículo 189 del Código Electoral del Estado de Michoacán”, p. 7.

González, M., y Mesri, P. A. (20I5). "Justiciabilidad de los derechos colectivos de los pueblos y comunidades indígenas". Cuestiones constitucionales, (32), 20 I-233. doi: https://doi.org/I0.1016/j.rmdc.2016.03.007

Hernández, R. (25 de noviembre de 2016)."Presumen anomalías en investigación de grupo armado en Pichátaro". Quadratín. Recuperado de: https://www.quadratin.com. $\mathrm{mx} /$ principal/presumen-anomalias-en-investigaciongrupo-armado-en-pichataro/

Instituto Electoral de Michoacán (20 de abril de 20 I 6a). Acuerdo No. IEM CG-07/2016. Recuperado de: http://iem.org.mx/ documentos/acuerdos/20I6/ACUERDO\%20QUE\%20 
PRESENTA\%20LA\%20COMISI\%C3\%93N\%20ELECTORAL\%2OPARA\%20LA\%20ATENCI\%C3\%93N\%20A\%20 PUEBLOS\%20IND\%C3\%8DGENAS\%2020\%20DE\%20 ABRIL\%20CG0720I6.pdf

Instituto Electoral de Michoacán (04 de mayo de 20I6b). Comunidades indígenas del oriente aprueban Reglamento de Consulta a Pueblos y Comunidades Indígenas del IEM. (Boletín creado el 0405 2016). Recuperado de: http://www.iem.org.mx/index.php/home/comunicacioninstitucional/noticias-relevantes/558-comunidades-indigenas-del-oriente-aprueban-reglamento-de-consulta-apueblos-y-comunidades-indigenas-del-iem

Monreal, P. (26 de abril de 20I6a). "Pichátaro escribirá historia como Cherán de obtener fallo favorable del TEPJF". Revolución 3.0. Recuperado de: http://michoacantrespuntocero.com/pichataro-escribira-historia-como-cherande-obtener-fallo-favorable-del-tepjf/

Monreal, P. (3I de octubre de 20I6b). "Tras cinco horas de negociaciones signa convenio Pichátaro con Ayuntamiento de Tingambato". Revolución 3.0. Recuperado de: http://michoacantrespuntocero.com/tras-cincohoras-de-negociaciones-signa-convenio-pichataro-conayuntamiento-de-tingambato/

Orozco, J. J. (201 I). "Los derechos humanos y el nuevo artículo I constitucional”. Revista IUS, 5(28), 85-98. Recuperado de: https://www.revistaius.com/index.php/ ius/article/view/66/61

Periódico Oficial del Gobierno Constitucional del Estado de Michoacán de Ocampo (29 de mayo de 2015). "Cuarta sección”, CLXII( I 7). Recuperado de: http://leyes.michoacan.gob.mx/destino/OI0565po.pdf

Periódico Oficial del Gobierno Constitucional del Estado de Michoacán de Ocampo (09 de agosto de 2016). " $7^{a}$ sección". 
Bibliografía
Quadratín (28 de enero de 2016a). "Tachan indígenas de discriminatorio Presupuesto de Egresos 2016”. Recuperado de: https://www.quadratin.com.mx/politica/Tachanindigenas-discriminatorio-Presupuesto-Egresos-20 I6/

Quadratín (24 de octubre de 2016b). "Aprueban comunidades del pueblo purépecha Reglamento de Consulta del IEM". Recuperado de: https://www.quadratin.com. $\mathrm{mx} /$ politica/aprueban-comunidades-del-pueblo-purepecha-reglamento-consulta-del-iem/

Ramírez, F. (3I de octubre de 20I6). “Dispondrá Pichátaro de 3 mdp para el inicio de 2017”. Quadratín. Recuperado de:https://www.quadratin.com.mx/principal/dispondrapichataro-3-mdp-inicio-20 I7/

Ramírez, L. (2007).“Remunicipalización en la región purhépecha de Michoacán: demanda contenida, representación negada”, en H. Martínez Barragán, L. Ramírez, H. R. Solís Gadea, y M. B. Valenzuela (coords.), Creación de nuevos municipios. Procesos y perspectivas (pp. 295-339). Guadalajara: Universidad de Guadalajara.

Santillán,V.M. (20I4). El ejercicio del poder desde la resistencia indígena. Cherán, Michoacán. 200 I-20 I 4 [tesis de maestría inédita]. Flacso: México. Recuperado de: https://flacso. repositorioinstitucional.mx/jspui/bitstream//026/28/I/ Santillan_VM.pdf

Sierra, T. (20|4). "La justiciabilidad de los derechos indígenas en el campo electoral: entre la universalidad de los derechos humanos y el derecho de autonomía". Trabajo presentado en el VII Seminario Internacional del Observatorio Judicial. Tribunal Electoral del Poder Judicial de la Federación. Oaxaca, Oaxaca. Recuperado de: http://portales.te.gob.mx/vii_observatorio/sites/ default/files/MTSierra_derechos\%20humanos $\% 20 y \% 20$ autonomia-\%20(20I4-I2-I2).pdf

Stavenhagen, R. (2008). Los pueblos indígenas y sus derechos. México: UNESCO. 
Suprema Corte de Justicia de la Nación (26 de mayo de 20 I 4). Bibliografía Contenido de la versión taquigráfica de la sesión pública ordinaria del pleno de la Suprema Corte de Justicia de la Nación, celebrada el lunes 26 de mayo de 2014. Acuerdo núm. 32/2012. Recuperado de: https://www.scjn.gob.mx/ PLENO/ver_taquigraficas/260520I4PO.pdf

Tribunal Electoral del Estado de Michoacán (07 de julio de 2015). Acuerdo plenario. Expediente: TEEM-AES-0/3/2015. Recuperado de: http://www.teemich.org.mx/adjuntos/ documentos/documento_559ea76f7ffc3.pdf

Tribunal Electoral del Poder Judicial de la Federación (27 de mayo de 2015). Acuerdo de sala juicios para la protección de los derechos político-electorales del ciudadano. Expedientes: SUP-JDC-364/2015 y SUP-JDC-533/2015, acumulados. Recuperado de: http://portal.te.gob.mx/colecciones/ sentencias/html/SUP/20 I5/JDC/SUP-JDC-00364-20I5Acuerdol.htm

Tribunal Electoral del Poder Judicial de la Federación (08 de mayo de 2016a). Juicio para la protección de los derechos político-electorales del ciudadano. Expediente: supJDC-I 865/2015. Recuperado de: http://www.te.gob.mx/ Informacion_juridiccional/sesion_publica/ejecutoria/ sentencias/SUP-JDC-I865-20I5.pdf

Tribunal Electoral del Poder Judicial de la Federación (24 de agosto de 2016b). Acuerdo de reencauzamiento. Juicio para la protección de los derechos político-electorales del ciudadano. Expediente: SUP-JDC-I73//20/6. Recuperado de: http://www.te.gob.mx/Informacion_juridiccional/ sesion_publica/ejecutoria/sentencias/SUP-JDC-I73I2016-Acuerdol.pdf

Tribunal Electoral del Poder Judicial de la Federación (05 de octubre de 2016c). Incidente de inejecución de sentencia. Juicio para la protección de los derechos político electorales del ciudadano. Expediente SUP-JDC-I 865/2015. Recuperado 
Bibliografía de: http://www.te.gob.mx/EE/SUP/20 I5/JDC/I865/ INC/I/SUP_20I5_JDC_I865_INC_I-609475.pdf-

Velázquez, V. (20I3). Reconstrucción del territorio comunal. El movimiento étnico autonómico en San Francisco Cherán Michoacán [tesis de maestría inédita]. CIESAS: Ciudad de México.

Ventura, M. C. (2003a). "De la disputa por la presidencia municipal a la conformación de regiones autónomas pluriétnicas". Estudios michoacanos, XI, 39I-4I8.

Ventura, M. C. (2003b). Disputas por el gobierno local en Tarecuato, Michoacán, 1942-1999. Zamora: El Colegio de Michoacán.

Ventura, M. C. (2012). "Proceso de autonomía en Cherán. Movilizar el derecho". Espiral Estudios sobre Estado y sociedad, XIX(55), I57-I75. Recuperado de: http:// www.espiral.cucsh.udg.mx/index.php/EEES/article/ view/526/546

Ventura Patiño, M. (10 abril de 2016a). Entrevista telefónica con juez de tenencia de Comachuén. Zamora, Michoacán.

Ventura Patiño, M. (29 de junio de 20/6b). Entrevista personal con Pavel Guzmán, joven militante del Frente Popular Emiliano Zapata en Pátzcuaro y miembro activo del CSIM. Morelia, Michoacán.

Ventura Patiño, M. (I8 de agosto de 20I6c). Entrevista personal con el diputado perredista Ángel Cedillo, entonces presidente de la Comisión de Pueblos Indígenas en el Congreso de Michoacán. Morelia, Michoacán.

Ventura Patiño, M. (I0 de septiembre de 20I6d). Nota de diario de campo sobre intervención del keri Pedro Chávez, miembro del actual Concejo Mayor de Cherán, en Foro de Consulta y Procesos Legislativos sobre los Derechos de los Pueblos Originarios. Morelia, Michoacán. 
Ventura Patiño, M. (10 de septiembre de 2016e). Nota en Bibliografía diario de campo sobre palabras de un comunero de Pichátaro en el Foro de Consulta y Procesos Legislativos sobre los Derechos de los Pueblos Originarios. Morelia, Michoacán.

Ventura Patiño, M. (02 de noviembre de 2016f). Entrevista telefónica con $\mathrm{FV}$, profesor y miembro del Consejo Comunal en 2006. Zamora, Michoacán.

Ventura Patiño, M. (I4 de noviembre de 20l6g). Entrevista personal con MR, exintegrante del Consejo Comunal. Nurío, Michoacán.

Ventura Patiño, M. (19 de diciembre de 2016h). Entrevista personal con Pavel Guzmán, joven militante del Frente Popular Emiliano Zapata en Pátzcuaro y miembro activo del CSIM. Morelia, Michoacán. 